\title{
Complications of ear mold impressions: two case reports
}

\author{
Clara Silva $\cdot$ Ana Margarida Amorim • \\ Carla Gapo $\cdot$ António Paiva
}

Received: 4 March 2014/Accepted: 29 July 2014/Published online: 29 August 2014

(C) Springer-Verlag Berlin Heidelberg 2014

\section{Introduction}

The performance of an ear mold is considered to be a safe and routine procedure. Complications are rare but can occur, namely the entrance of impression material in the middle ear in case of iatrogenic perforation or in a preexistent perforation [1-4].

We report two cases in which the impression material of ear mold entered into the middle ear through a pre-existent perforation.

\section{Case report 1}

An 8-year-old male, with a past history of right chronic otitis media, with tympanic membrane perforation was advised to use an external auditory canal protector for preventing the entrance of water in the ear. This was a measure to prevent the occurrence of infections before further surgery. During the process of impression taking, the patient experienced extreme pain and worsening of hearing loss and the ear mold was impossible to remove. He was referred to the ENT emergency department where in otoscopy, it was possible to see a foreign material under the tympanic membrane (Fig. 1). Audiometry evidenced a conductive hearing loss with an air bone GAP of $45 \mathrm{~dB}$ (Fig. 2a). The computerized tomography (CT) demonstrated the filling of the middle ear and antrum, with a soft tissue density material, without bone erosion (Fig. 2b). A

C. Silva $(\varangle) \cdot$ A. M. Amorim · C. Gapo · A. Paiva Otorhinolaryngology Department, Centro Hospitalar e Universitário de Coimbra, Praceta Mota Pinto, 3000-075 Coimbra, Portugal

e-mail: claranetosilva@gmail.com right atticotomy with type I tympanoplasty, with removal of the foreign material was performed. The postoperative period held uneventful.

\section{Case report 2}

A 62-year-old female with left chronic otitis media and a right canal wall down cavity, was using bilateral hearing aids for her deafness. While taking a hearing aid impression, she had intense pain and worsening of hearing loss in the left ear. She was immediately sent to the emergency room and in otoscopy it was possible to see a strange material through the tympanic membrane perforation site (Fig. 3). Audiometry demonstrated a mixed bilateral hearing loss with a pure tone average of $80 \mathrm{~dB}$ in right and $70 \mathrm{~dB}$ in the left and with an air bone GAP of $35 \mathrm{~dB}$ in the right ear and a $10 \mathrm{~dB}$ in the left ear (Fig. 4a). A CT was performed and evidenced a soft tissue density within the left middle ear cavity (Fig. 4b). An anterior tympanotomy with remotion of a "white material" was done (Fig. 5). In the follow-up period the perforation was closed, with no other events.

\section{Discussion}

The cases presented lead us to some important considerations, especially that in the ear mold fitting complications may occur. Even though there are some case reports and short series descriptions such complications are rarely reported but are likely to be more frequent $[1-3,5]$.

These complications range from a simple foreign body in the ear canal or the mastoid cavity (through perforation) to traumatic tympanic membrane (TM) perforation, ossicular 


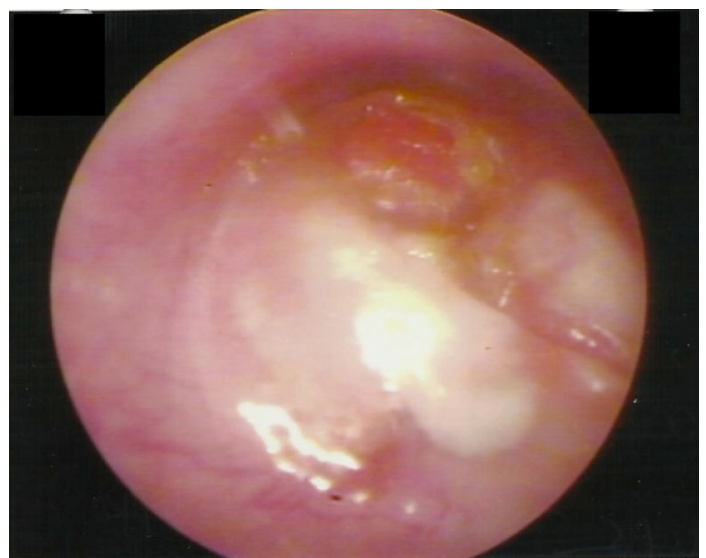

Fig. 1 Otoscopy: foreign material under the tympanic membrane

chain discontinuity and even involvement of the facial nerve [6]. There is a case of perilymph leakage secondary to subluxation of stapes reported by Leong et al. [7].

Patients at particular risk should be informed [1, 4]. We mention those with altered anatomy of the ear, such as TM perforations, retracted TM pockets, tympanostomy tubes and canal wall down mastoid cavities. The procedure is not contraindicated in these conditions but the technician or the doctor, should inform the patients prior to it $[4,8]$.

The symptoms related depend on the length of time that the foreign body is in the ear. In the acute stage, patients present acute pain, tinnitus, hearing loss, and dizziness during the process of mold-making [1]. In the cases of asymptomatic patients, if the hearing aid dispenser is unaware that the hearing aid impression mold material is retained, the onset of symptoms may take several years. At that time, the symptoms are often similar to the ones of chronic otitis media, such as intractable otorrhea and formation of granulation tissue as reported by Lee et al. and Dhawan et al. [1, 2].

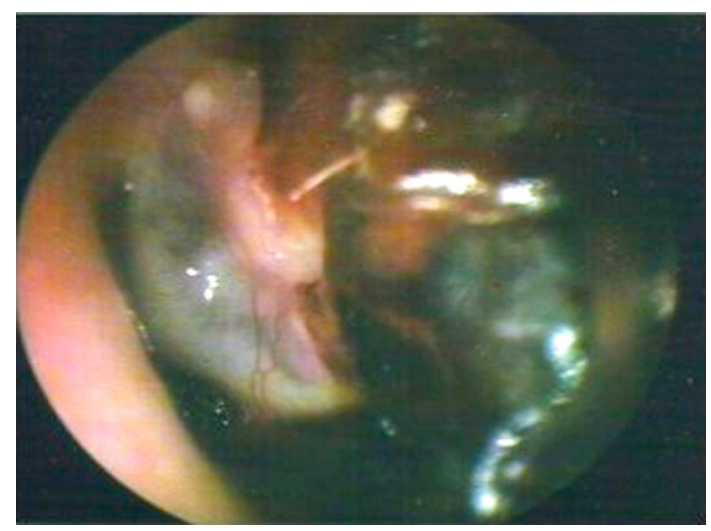

Fig. 3 Otoscopy: strange material in the tympanic membrane perforation site

A CT scan of the temporal bone may be required to adequately assess the extension of middle ear and/or mastoid penetration by the impression material $[1,4]$.

The treatment of retained impression material, in some instances, like the reported cases, is surgical removal. Well-established surgical techniques, including meatoplasty, middle ear exploration, atticotomy or tympanomastoidectomy with a facial recess approach, enable proper visualization and safe removal of impacted impression material [1, 6]. The elastic nature of silicone impression material makes it difficult to remove under local anesthesia [8]. In some cases it is possible to remove it in the office under microscope control, by an experienced doctor $[5,6]$.

Mold impressions taken by untrained hands can cause serious trauma leading to further hearing impairment and disability $[2,3,5]$. Other than a careful history taking, it is important to perform an adequate assessment of a clean external ear canal in order to have a complete visualization of the tympanic membrane $[4,6]$. Care should be taken to put an adequate protective device (a cotton plug) in the a

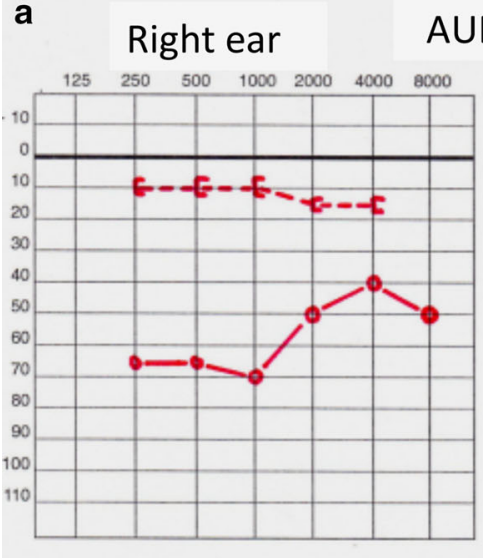

AUDIOMETRY

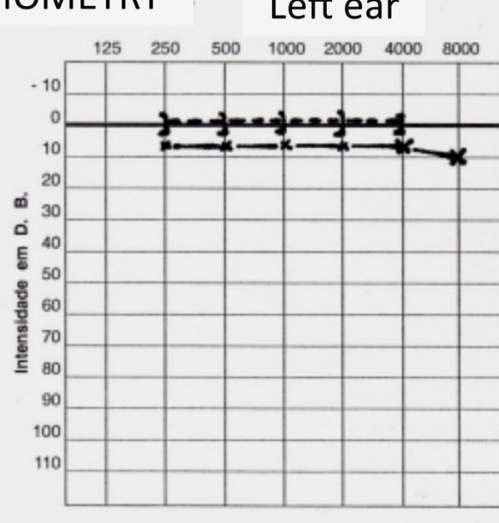

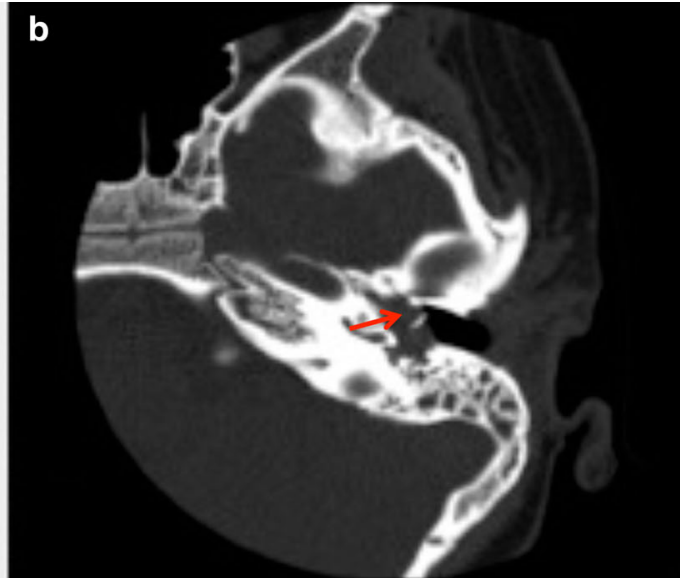

Fig. 2 a Conductive hearing loss at right ear. b CT showing the filling of antrum and middle ear with soft tissue density material 


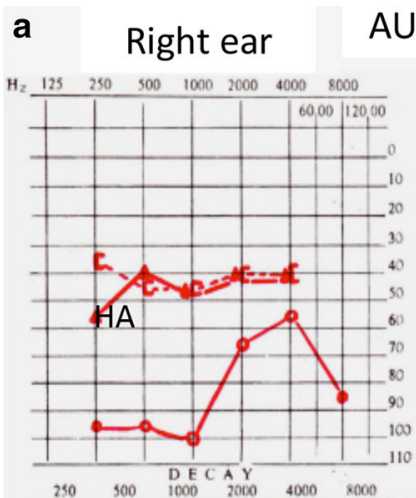

AUDIOMETRY
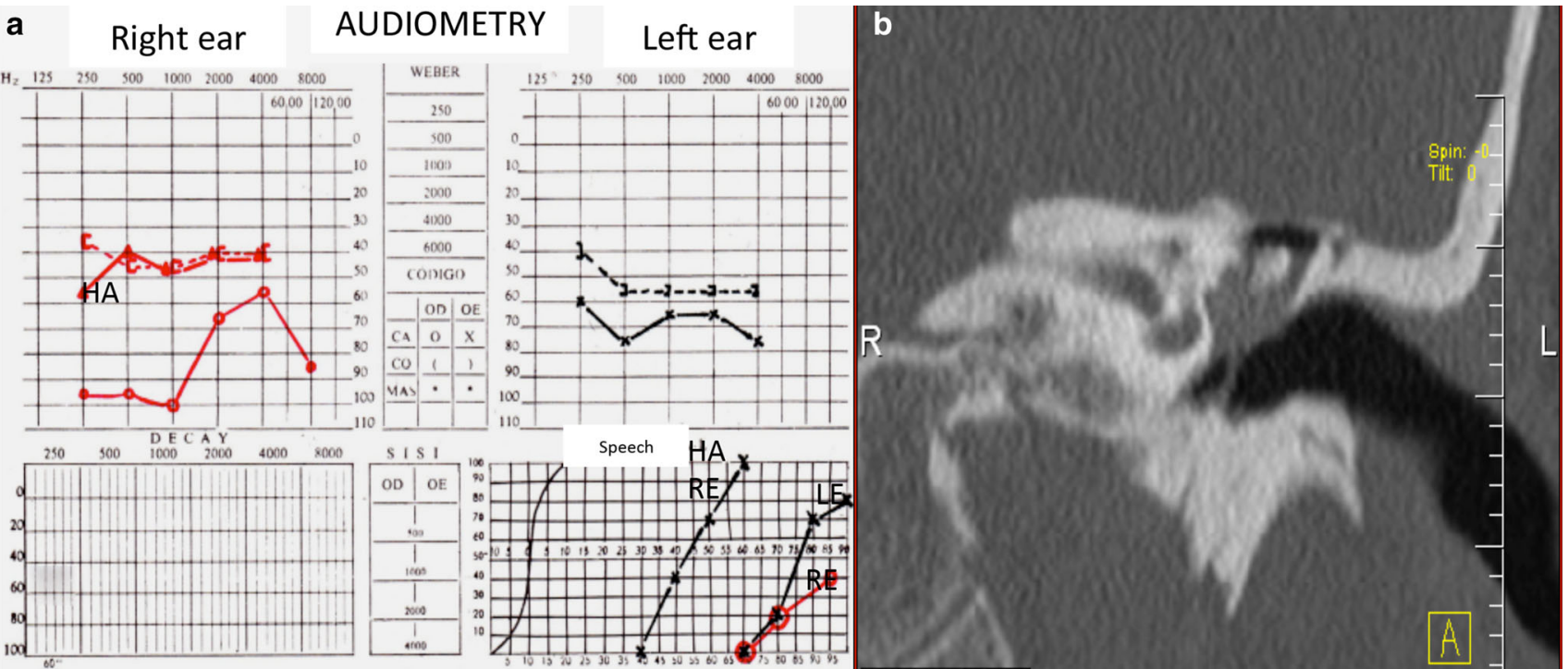

Fig. 4 a Audiometry: mixed hearing loss bilaterally with an air bone GAP of $10 \mathrm{~dB}$ in the left ear and $35 \mathrm{~dB}$ in the right ear. b CT showing soft tissue density in the left middle ear cavity. $H A$ hearing aid, $R E$ right ear, $L E$ left ear

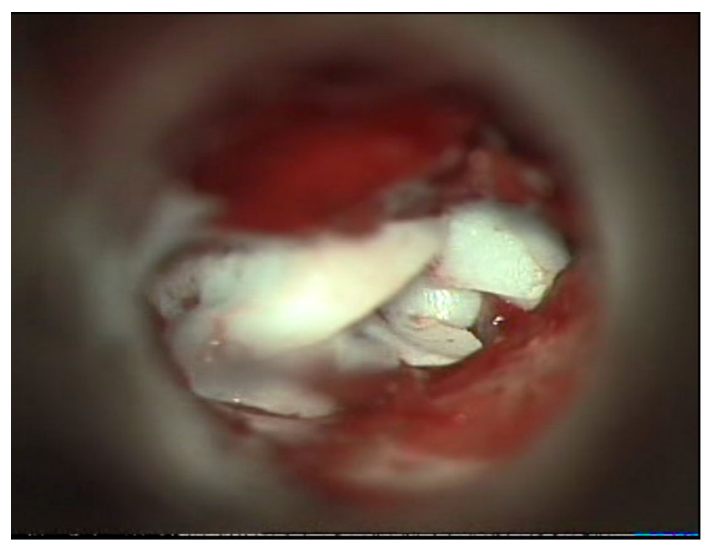

Fig. 5 Impression material being removed from the middle ear cavity

external canal prior to the mold impression making $[5,7$, 9]. The selected material for the mold should be appropriate, like the silicone that is more viscous, and care should be taken not to push it in the ear canal with too much pressure to prevent the rupture of an intact tympanic membrane $[3,4,7,9]$. The ear canal should not be sealed off by the piston so that if the pressure rises in the ear canal, the material has space through which to flow instead of causing trauma to the tympanic membrane $[3,4,9]$.

In summary, the majority of the situations are avoidable. It is important to follow strictly proper protocols during the process of making ear mold impression and be aware of the possible hazard complications. The mold should be made by an experienced person trained in this area and prevention should be the mainstay of the treatment. It is recommended that a patient with an impacted mold impression should be referenced to an otorhinolaryngologist. So, a close cooperation between hearing dispensers and otorhinolaryngologist must be present.

Conflict of interest No conflict of interest.

\section{References}

1. Lee DH, Cho HH (2012) Otologic complications caused by hearing aid mold impression material. Auris Nasus Larynx 39:411-414

2. Dhawan N, Gupta N, Goyal A, Singh V (2008) Otoplast in the middle ear cleft-a rare complication of hearing aid fitting and its surgical management. Indian J Otolaryngol Head Neck Surg 60:234-237

3. Awan MS, Iqbal M, Sardar ZI (2007) Iatrogenic insertion of impression mould into the middle ear and mastoid and its retrieval after 9 years: a case report. J Med Case Rep 1:3

4. Jacob A, Morris TJ, Welling DB (2006) Leaving a lasting impression: ear mold impressions as middle ear foreign bodies. Ann Otol Rhinol Laryngol 115:912-916

5. Syms CA, Nelson RA (1998) Impression-material foreign bodies of the middle ear and external auditory canal. Otol Head Neck Surg 119:406-407

6. Kohan D, Sorin A, Marra S, Gottlieb M et al (2004) Surgical management of complications after hearing aid fitting. Laryngoscope 114:317-322

7. Leong SC, Banhegyi G, Panarese A (2012) Serious complications during aural impression-taking for hearing aids: a case report and review of the literature. Ann Otol Rhinol Laryngol 121:516-520

8. Shashinder S, Tang IP, Velayutham P, Rahamat O et al (2008) Foreign body in the middle ear, a hearing aid complication. Med J Malays 63:267-268

9. Hof JR, Kremer B, Manni JJ (2000) Mould constituents in the middle ear, a hearing-aid complication. J Laryngol Otol 114:50-52 